\title{
Hydrothermal pretreatment of oxytetracycline fermentation residue: Removal of oxytetracycline and increasing the potential for anaerobic digestion
}

\author{
Mohammed Awad ${ }^{1}$, Zhe Tian ${ }^{1,2^{\dagger}}$, Yu Zhang ${ }^{1,2}$, Min Yang ${ }^{1,2}$, Wenjuan Yin ${ }^{3}$, Liping Dong \\ ${ }^{1}$ State Key Laboratory of Environmental Aquatic Chemistry, Research Center for Eco-Environmental Sciences, Chinese Academy of Sciences, Beijing \\ 100085, China \\ ${ }^{2}$ University of Chinese Academy of Sciences, Beijing 100049, China \\ ${ }^{3}$ State environmental protection engineering center for harmless treatment and resource utilization of antibiotic residues, Xinjiang 835007, China
}

\begin{abstract}
The presence of high level of antibiotics in the antibiotic fermentation residue is one of the main reasons that prevent their direct disposal or further use as a resource. In this study, the feasibility of using the hydrothermal pretreatment for removing oxytetracycline (OTC) from its fermentation residue and enhancing anaerobic digestion was evaluated under different temperatures i.e. $110,130,150$ and $170^{\circ} \mathrm{C}$. The results showed that the removal rate of OTC increased as a function of temperature, and hydrothermal treatment at $130^{\circ} \mathrm{C}$ for 5 min was found sufficient to reduce the concentration of OTC from $3.9 \mathrm{mg} / \mathrm{g}$ to less than the detection limit (i.e., $0.25 \mathrm{ng} / \mathrm{g}$ ). Biochemical methane potential tests showed that the cumulative methane production over $23 \mathrm{~d}$ was $73.7,215.9,656.8$, and $439.0 \mathrm{NmL} \mathrm{CH}_{4} / \mathrm{gVS}$ for the raw residue and the residue treated at 130,150 , and $170^{\circ} \mathrm{C}$ for $5 \mathrm{~min}$, respectively. At the same time, the abundances of tetracycline resistance genes were reduced by hydrothermal treatments followed by anaerobic digestion. Conclusively, it is suggested that hydrothermal treatment at $150^{\circ} \mathrm{C}$ for 5 min was found beneficial for OTC fermentation residues ensuring the removal of OTC and further use of the residue for anaerobic digestion.
\end{abstract}

Keywords: Antibiotic fermentation residue, Biochemical methane potential, Oxytetracycline, Thermal hydrolysis

\section{Introduction}

Oxytetracycline (OTC) is one of the broad-spectrum antibiotics widely used in livestock farming and aquaculture worldwide. OTC is produced by submerged fermentation of Streptomyces rimosus [1] which yields large amounts of OTC fermentation residue at the end of the fermentation process. Because of the high level of residual antibiotics, the antibiotic fermentation residue have been added into the list of hazardous materials [2], and are prohibited to be used as animal feed or fertilizer and their open dumping without proper treatment is also prohibited [3]. At present, incineration is the most commonly used treatment technology for antibiotic fermentative residue, but it is very expensive and energy-intensive due to the high moisture content in the residue, which becomes a great economic burden to the manufacturers [4]. Therefore, it is necessary to explore alternative technology to reduce the treatment cost and transform the antibiotic fermentation residue into a beneficial material.

Upon successful removal of the antibiotics, the antibiotic fermentation residue can be utilized as carbon-rich biomass [5]. Although, Fenton process, ozonation, and other advanced oxidation processes are found effective for the reduction of OTC [6, 7], they have certain shortcomings including high chemical oxygen demand (COD) and high level of suspended solids in the residue [8]. Since antibiotics are prone to hydrolysis at elevated temperatures, hydrothermal treatment may be a suitable alternative technology for their successful removal from the residue [9]. At present, hydrothermal pretreatment has been applied in the treatment of waste mother liquor from the antibiotic fermentation process [10]. Recently, we reported that hyperthermophilic anaerobic digestion process operated at $70^{\circ} \mathrm{C}$ for $7 \mathrm{~d}$ could simultaneously remove antibiotics, reduce antibiotic resistance genes (ARGs) and enhance the solubility of spiramycin fermentation residue [11]. To further improve efficiency and reduce processing
This is an Open Access article distributed under the terms of the Creative Commons Attribution Non-Commercial License (http://creativecommons.org/licenses/by-nc/3.0/) which permits unrestricted non-commercial use, distribution, and reproduction in any medium, provided the original work is properly cited.
Received May 21, 2020 Accepted July 23, 2020

${ }^{\dagger}$ Corresponding author

Email: zhetian@rcees.ac.cn

Tel: +86-010-62843038 Fax: +86-10-62923541 
time, the thermal hydrolysis process operated at more than $120^{\circ} \mathrm{C}$ $[12,13]$ has been developed. For example, CambiTHP ${ }^{\text {тм }}$ and Biothelys ${ }^{\circledR}$, two commercially available hydrothermal processes with an operation temperature $165^{\circ} \mathrm{C}$, have been established as the pretreatment units prior to anaerobic digesters for treating municipal sewage sludge [14]. The hydrothermal treatment has been proved to significantly enhance the solubility of biomass and thus greatly increase biogas production [15, 16]. Recently, Pei et al. [16] found that thermal hydrolysis at $170^{\circ} \mathrm{C}$ for 30 min could effectively reduce the abundance of antibiotic resistance genes in pharmaceutical and municipal waste sludge. The hydrothermal process has also been tested for the treatment of streptomycin and cephalosporin $\mathrm{C}$ residues, where an improved biodegradability of the residues with complete removal of the residual antibiotics were proved [17-19]. Considering the facile hydrolysis of OTC at high temperatures [20], hydrothermal treatment can be considered highly desirable for the treatment of OTC fermentation residues, however, its feasibility so far remains unclear.

In the present study, the feasibility of hydrothermal hydrolysis as a pretreatment method of the OTC fermentation residue was evaluated over a temperature range from 110 to $170^{\circ} \mathrm{C}$ for a period of 5 - $30 \mathrm{~min}$. The effect of temperature on the removal of OTC, reduction of ARGs, and enhancement of solubility were investigated first. Then the biochemical methane potentials (BMP) of the raw and treated residues were tested using Automatic Methane Potential Test System (AMPTS), and the changes of ARGs and microbial communities before and after the BMP test were detected using quantitative PCR analysis and Miseq sequencing. The results of this study provide guidance for the establishment of a viable strategy for the treatment of antibiotic fermentation residues.

\section{Materials and Methods}

\subsection{Experimental Setup}

In this study, a high-pressure stainless steel reactor covered with a Teflon liner(effective volume, 1.2 liters) was used for the thermophilic hydrolysis experiment(Weihai Borui Chemical Machinery, China). The OTC residue acquired from an OTC manufacturer in Hebei Province, which mainly produces oxytetracycline dehydrate via fermentation of Streptomyces rimosus. The fermentation residue was collected from the production workshop as soon as it was separated from the fermentation broths. The collected residue was stored at $4^{\circ} \mathrm{C}$ before use, and its characteristics are provided in Table 1 . For each test, approximately $0.5 \mathrm{~L}$ of the residue was

Table 1. Characteristics of The OTC Fermentation Residue Used in The Experiment

\begin{tabular}{lc}
\hline Parameter & Value \\
\hline $\mathrm{pH}$ & $5.42 \pm 0.0$ \\
$\mathrm{TSS}(\mathrm{g} / \mathrm{L})$ & $91.5 \pm 1.2$ \\
$\mathrm{VSS}(\mathrm{g} / \mathrm{L})$ & $74.8 \pm 0.4$ \\
$\mathrm{VSS} / \mathrm{TSS}(\%)$ & $81.8 \pm 0.0$ \\
$\mathrm{sCOD}(\mathrm{mg} / \mathrm{L})$ & $9443 \pm 233$ \\
$\mathrm{NH}_{3}-\mathrm{N}(\mathrm{mg} / \mathrm{L})$ & $244 \pm 23$ \\
$\mathrm{OTC}$ content $(\mathrm{mg} / \mathrm{g})$ & $3.9 \pm 0.1$ \\
\hline
\end{tabular}

added to the hydrothermal reactor. The hydrothermal treatment was performed at various temperatures (i.e., 110, 130, 150, and $170^{\circ} \mathrm{C}$ ) and for different time periods (5, 10, 15, 25, and $\left.30 \mathrm{~min}\right)$. During the treatment, the biomass was mixed at a speed of $180 \pm 5$ $\mathrm{rpm}$. Samples for antibiotics analysis were stored at $-20^{\circ} \mathrm{C}$ until use.

\subsection{Analytical Methods}

In order to characterize the performance of hydrothermal treatment on enhancing solubility of OTC residue, the concentrations of solubilized COD and ammonia nitrogen were measured. As for solubilized COD, the residue was first centrifuged at 10,000 rpm for10 min and then filtrated using a $0.45 \mu \mathrm{m}$ filter. COD of the filtrate was determined using Spectroquant photometer NOVA 60 (Merck D armstadt, Germany). Ammonia nitrogen was detected using the Nessler reagent spectrophotometric method. Total solids and volatile solids were determined according to standard methods [21].

\subsection{Determination of Oxytetracycline in Fermentation Residue}

The procedure described by Qiao et al. [22] and Zhu et al. [23] was used for the analysis of OTC in the fermentation residue with some modifications. Briefly, $0.1 \mathrm{~g}$ of $\mathrm{Na}_{2} \mathrm{EDTA}$ and $10 \mathrm{~mL}$ extraction buffer (phosphate buffer $(\mathrm{pH}=3.0)$ : acetonitrile $=1: 1(\mathrm{v} / \mathrm{v}))$ were added to $50 \mathrm{mg}$ freeze-dried fermentation residue sample. The mixture was vortexed for $30 \mathrm{~s}$ and sonicated for $20 \mathrm{~min}$, followed by centrifugation at 3,000 rpm for $20 \mathrm{~min}$, and then the supernatant was decanted into a new glass bottle. This step was repeated twice. The combined supernatant was diluted with distilled water to 500 $\mathrm{mL}$, followed by adding $1 \mathrm{~mL}$ phosphate buffer $(\mathrm{pH}=3.0)$. The extract was subjected to solid-phase extraction using Oasis HLB extraction cartridges. The antibiotic fraction eluted from the cartridges was dissolved in $0.5 \mathrm{~mL}$ of methanol. Before UPLC-MS/MS analysis, the methanol extracts were diluted at 1:1 (v/v) with pure water. Analysis of the extracts was performed by a Waters ACQUITY UPLCTM system (USA) equipped with a Waters Micromass Quattro Premier XE (triple-quadrupole) detector following Zhu et al. [23]. Samples were analyzed in triplicate. Recovery was determined by spiking OTC standard into the $170^{\circ} \mathrm{C}$ hydrolyzed residue $(5$ $\mathrm{min}$ ) at the concentration of $400 \mu \mathrm{g} / \mathrm{kg}$, followed by the same extraction and determination procedure described above. The average recovery of OTC was $85.6 \% \pm 7.1 \%$.

\subsection{BMP Test}

In order to compare the performance of different hydrothermal pretreatment conditions for transforming the OTC fermentation residue into beneficial material, the methane formation potentials of the residue with and without hydrothermal pretreatment were tested in duplicate using the Automatic Methane Potential Test System (AMPTS 2.0) (Bioprocess Control, Sweden). Since the hydrothermal treatment at $110^{\circ} \mathrm{C}$ was not able to completely remove the residual antibiotic (Table 2), it was excluded from the BMP test. The test was performed in a $500 \mathrm{~mL}$ glass bottle containing $400 \mathrm{~mL}$ of substrate and inoculum at a ratio of 1:1. Before the $\mathrm{BMP}$ test, the $\mathrm{pH}$ of the residue with or without pretreatment was adjusted to around 7.0. The inoculum was obtained from the mesophilic digester of the Gaobeidian Wastewater Treatment Plant in Beijing (Table S1). The system was operated at mesophilic condition 
Table 2. Removal of OTC from The Fermentation Residue Under Different Treatment Temperatures and Times

\begin{tabular}{|c|c|c|c|c|c|c|}
\hline \multicolumn{7}{|c|}{ Concentration of OTC $(\mu \mathrm{g} / \mathrm{g})$} \\
\hline Time/min & & 5 & 10 & 15 & 25 & 30 \\
\hline \multirow{4}{*}{$\begin{array}{l}\text { Temperature } \\
\left({ }^{\circ} \mathrm{C}\right)\end{array}$} & 110 & $29.9 \pm 3.5$ & $33.9 \pm 3.6$ & $14.9 \pm 0.6$ & $14.6 \pm 0.8$ & $15.2 \pm 0.3$ \\
\hline & 130 & $\mathrm{BDL}^{*}$ & BDL & BDL & BDL & BDL \\
\hline & 150 & BDL & BDL & BDL & BDL & BDL \\
\hline & 170 & BDL & BDL & BDL & BDL & BDL \\
\hline
\end{tabular}

*BDL: Below Detection Limit $(<0.25 \mathrm{ng} / \mathrm{g})$

$\left(37^{\circ} \mathrm{C}\right)$ for $23 \mathrm{~d}$, which is often used for anaerobic mesophilic digestion studies[24-26] and gas production was automatically recorded by AMPTS 2.0. The methane formation potential was expressed as the volume of produced methane/g of VS.

\subsection{DNA Extraction and Quantitative PCR Analysis}

Total DNA was extracted from 0.5 mg of all samples using a FastDNA SPIN kit for soil (MP Bio, USA), according to the manufacturer's instructions. The quality and quantity of the extracted DNA were checked by using NanoDrop and gel electrophoresis. For each sample, bacterial $16 \mathrm{~S}$ rRNA gene and eight frequently reported tetracycline resistance genes including tetA, tetC, tetG, tetK, tetL, tetM, tet $O$, and tet $X$ were examined. Only three tet genes namely tet $A$, tet $O$, and tet $X$ were successfully detected. The quantification was carried by SYBR green quantitative real-time PCR (qPCR) using LightCycler 96 (Roche Diagnostics GmbH, Germany) as previously described [27]. The amplification was carried out in a $25 \mu \mathrm{L}$ reaction mixture. All reactions were performed in triplicate. The temperature program was set as one cycle of $95^{\circ} \mathrm{C}$ for $10 \mathrm{~min}$ followed by 40 cycles of $95^{\circ} \mathrm{C}$ for $15 \mathrm{~s}$ and annealing temperature for $1 \mathrm{~min}$. The primers' information and the annealing temperature of different ARGs are shown in Table S2 in the supporting material. Gene abundance was calculated using software supplied with LightCycler. A standard curve was generated using a given concentration of standard plasmids containing each target gene. The correlation coefficients $\left(\mathrm{R}^{2}\right)$ for standard curves and amplification efficiencies based on curve slopes were calculated to ensure reliable amplification. The $\mathrm{R}^{2}$ values for all the curves were over 0.99 and efficiency between $92 \%$ and $108 \%$. The specificity of the PCR was also assured by melting curves and gel electrophoresis.

\subsection{Miseq Sequencing}

Microbial community composition of different samples of the BMP test was analyzed using Illumina MiSeq sequencing. The sequencing was performed using the protocol described by Tian et al. [27]. The DNA samples were used to amplify the V4-V5 hypervariable regions of the 16S rRNA gene using the primers set of 515F/907R [28]. DNA was amplified in triplicate for each sample. PCR amplicons were pooled together and purified by Agarose Gel DNA purification kit (TaKaRa). The sample libraries were pooled, and paired-end sequencing was conducted with an Illumina MiSeq platform (Illumina, USA) according to the standard protocols. Amplicon data analysis including quality filtration, chimeras check, and taxonomic classification were conducted following Tian et al. [27]. The raw reads were deposited into the NCBI Sequence Read Archive
(SRA) database with accession no. PRJNA612953.

\subsection{Statistical Analysis}

The significant difference of the tet genes and other parameters between different treatments was compared using ANOVA (SPSS 22.0, IBM, USA). The $p$-value was considered statistically significant at $p<0.05$. Clustering analysis and Heatmap of the bacteria genera in digested sludge after the BMP test were generated using HemI [29].

\section{Results and Discussion}

\subsection{Removal of Antibiotics from OTC Fermentation Residue under Different Hydrothermal Pretreatment Conditions}

The residual OTC concentrations under different hydrothermal treatment conditions are presented in Table 2. It is clear that the hydrothermal treatment was quite effective even at a temperature of $110^{\circ} \mathrm{C}$ with the residual OTC concentration decreasing from $3.9 \pm 0.1 \mathrm{mg} / \mathrm{g}$ to $29.9 \pm 3.5 \mu \mathrm{g} / \mathrm{g}$ (removal, 99.2\%) for $5 \mathrm{~min}$, and further to $14.9 \pm 0.6 \mu \mathrm{g} / \mathrm{g}(99.6 \%)$ by extending the treatment time to $15 \mathrm{~min}$. However, the residual OTC concentration was not further reduced even by extending the treatment time to 30 min, suggesting that higher temperature was required to allow complete removal of OTC. When the temperature was increased to $130^{\circ} \mathrm{C}$, the residual OTC was decreased to below detection limit $(<0.25 \mathrm{ng} / \mathrm{g})$ after $5 \mathrm{~min}$ treatment, indicating that $130^{\circ} \mathrm{C}$ was optimum temperature threshold for completely removing OTC from the fermentation residue.

There are a few other studies that also focused on the hydrothermal treatment of fermentation residues. For instance, Zhang et al. [17] performed the hydrothermal process for the treatment of two types of cephalosporin $\mathrm{C}$ fermentation residues that contain different concentrations of saccharides. They reported that hydrothermal pretreatments at 200 and $180^{\circ} \mathrm{C}$ for $20 \mathrm{~min}$ were sufficient for the complete decomposition of cephalosporin $\mathrm{C}$ in low and high saccharide content of antibiotic fermentation residues, respectively. Sun et al. [30] evaluated the hydrothermal pretreatment of sewage sludge at $160^{\circ} \mathrm{C}$ for $30 \mathrm{~min}$ and found decline in tetracycline concentration from $68.6 \mathrm{ng} / \mathrm{g}$ to below detection limit (12 ng/g). OTC was found to be easily hydrolyzed both in water and soil when the temperature is higher than $45^{\circ} \mathrm{C}[31,32]$. Recently, Yi et al. [10] reported that the half-life $\left(\mathrm{t}_{1 / 2}\right)$ of OTC in water at $\mathrm{pH} 5$ and temperature $85^{\circ} \mathrm{C}$ was just $0.26 \mathrm{~h}$, and an increase of $10^{\circ} \mathrm{C}$ accelerates the OTC hydrolysis rate by $1.74-5.58$ fold. This 
study demonstrated that even adsorbed by the fermentation residue, OTC could be completely hydrolyzed at a temperature of $130^{\circ} \mathrm{C}$. Meanwhile, the major OTC hydrolysis products were found as 4-epioxytetracycline, $\alpha$-apo-oxytetracycline and $\beta$-apo-oxytetracycline [33], whose potencies are only equivalent to $0.7 \%$, $0.3 \%$ and $0.7 \%$ of that of the parent compound, respectively [34]. Therefore, the generated OTC hydrolysis products might not put a selection pressure on environmental bacteria for development of antibiotic resistance during the subsequent application of the hydrolyzed residue.

\subsection{Solubilization of OTC Fermentation Residue during Hydrothermal Pretreatment}

The solubilization effects of the OTC fermentation residue under different hydrothermal treatment conditions were also investigated by monitoring the changes of soluble COD and $\mathrm{NH}_{3}-\mathrm{N}$. As shown in Fig. 1, the hydrothermal treatment was quite effective in the solubilization of the fermentation residue, resulting in a marked release of soluble organic substances and $\mathrm{NH}_{3}-\mathrm{N}$. The soluble COD increased from $9,443 \mathrm{mg} / \mathrm{L}$ to $29,730 \mathrm{mg} / \mathrm{L}$ at a temperature of $110^{\circ} \mathrm{C}$ for $5 \mathrm{~min}$. Extension of treatment time did not significantly affect the solubilization effects of the fermentation residue. Similar to the OTC removal, elevating the temperature to $130^{\circ} \mathrm{C}$ led to the increase of soluble COD to $47,072 \mathrm{mg} / \mathrm{L}$, however further elevating treatment temperature did not lead to a perceptible increase in soluble COD concentration. $\mathrm{NH}_{3}-\mathrm{N}$ release on the other hand was dramatically increased with the increase of temperature, but was found indifferent to treatment time variation. The concentration of $\mathrm{NH}_{3}-\mathrm{N}$ was increased from $244 \mathrm{mg} / \mathrm{L}$ in raw residue to 684 , 781 and $798 \mathrm{mg} / \mathrm{L}$ for the samples pretreated at 110,130 and $150^{\circ} \mathrm{C}$, respectively. On further increase to $170^{\circ} \mathrm{C}$, the concentration of $\mathrm{NH}_{3}-\mathrm{N}$ was increased to $976.6 \mathrm{mg} / \mathrm{L}$. It is possible that the released proteins were further hydrolyzed to release $\mathrm{NH}_{3}-\mathrm{N}$ at a higher temperature. Similar to soluble COD, the extension of treatment time did not enhance the release of $\mathrm{NH}_{3}-\mathrm{N}$ to a significant level, which was consistent with previous studies [12, 35]. The increase of $\mathrm{COD}$ and $\mathrm{NH}_{3}-\mathrm{N}$ should be attributed to the decomposition of intracellular proteins or exopolymers [36]. The solubilization con- ditions may vary for different biomasses. In a previous study, $\mathrm{Li}$ et al.[4] found that a significant release of COD was achieved at $160^{\circ} \mathrm{C}$ for $60 \mathrm{~min}$ for the hydrothermal pretreatment of antibiotic mycelial residue. Further, increasing the temperature to $180^{\circ} \mathrm{C}$ resulted in a decrease in COD solubilization, which was attributed to the polymerization of smaller molecules. Based on the above results, hydrothermal treatment is found feasible for quickly removing antibiotics and enhancing the solubility of the OTC fermentation residue, and the hydrolyzed residue might be a potential substrate for further use.

\subsection{Changes of tet genes after Hydrothermal Pretreatment}

The quantifications of three tet genes namely tetA, tet $O$ and tet $X$ were conducted to examine their response to different hydrothermal treatments with a fixed retention time of $5 \mathrm{~min}$. The occurrence of the tet genes is presented in copy numbers per dry mass (Fig. 2a) and normalized to 16S rRNA genes (Fig. 2 (b)), respectively. The absolute abundances of tet $A$ and tet $X$ were significantly ( $p$ $<0.001$ ) decreased from $6.1 \times 10^{8}$ and $3.3 \times 10^{7}$ copies/g in the raw residue to $9.3 \times 10^{6}$ and $3.3 \times 10^{6}$ copies $/ g$, respectively, at a temperature of $130^{\circ} \mathrm{C}$. A similar reduction performance for both genes was achieved at 150 and $170^{\circ} \mathrm{C}$ treatments (Fig. 2 (a)). As for tetO, its abundance was reduced from $3.7 \times 10^{5} \mathrm{copies} / \mathrm{g}$ to $1.5 \times 10^{5}$ and $1.3 \times 10^{4}$ copies/g with the increase of the temperature to 150 and $170^{\circ} \mathrm{C}$, respectively. Similar results on the reduction of the absolute abundances of the tet genes and some other resistant determinants by hydrothermal treatment of fermentation residues and waste activated sludge have been reported by previous studies $[16,37,38]$. This is understandable since abundant DNA including ARGs will be released during hydrothermal treatment, and it is known that DNA is sensitive to high temperatures, particularly at temperatures higher than $90^{\circ} \mathrm{C}$ [39]. As shown in Fig. 2 (b), however, the relative abundance of the three tet genes, particularly tet $A$ and tet $X$, increased during the hydrothermal treatment. Wang et al. [37] also found that the relative abundances of tet genes in sewage sludge were increased after thermal hydrolysis treatment $\left(120^{\circ} \mathrm{C}\right.$ for $\left.60 \mathrm{~min}\right)$, which suggested that the 16S rRNA genes are more susceptible to hydrothermal conditions than ARGs. It
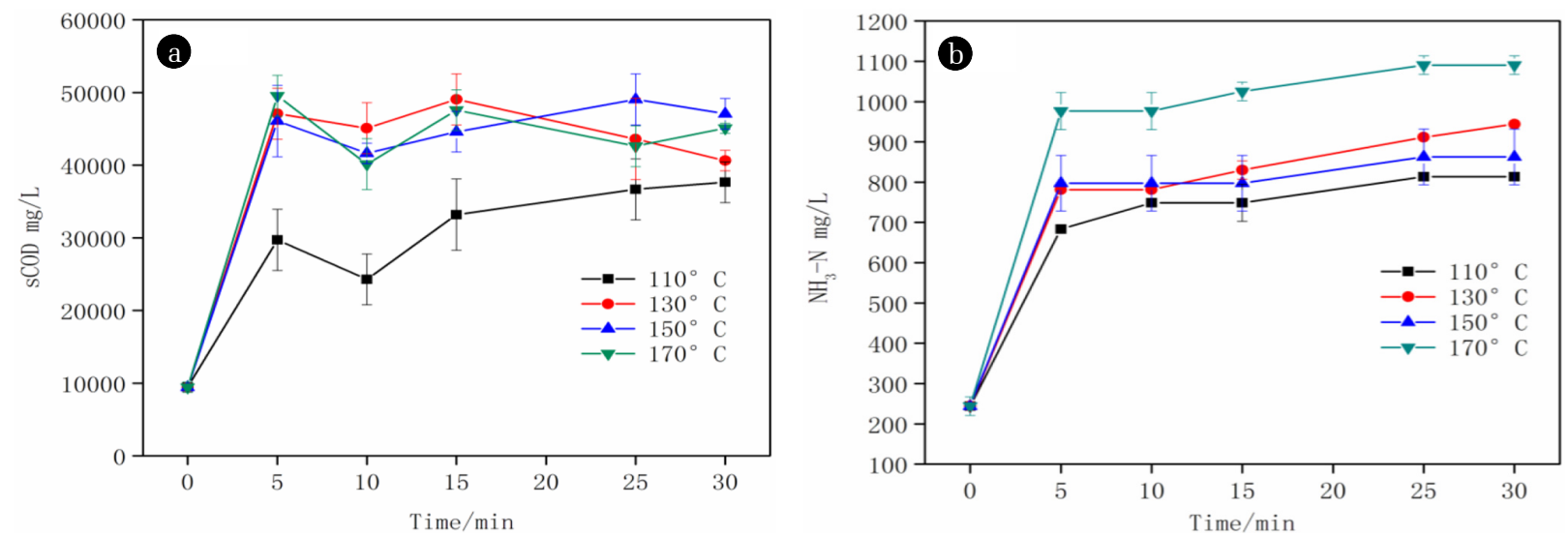

Fig. 1. Solubilization effects of OTC residue under different hydrothermal treatment conditions: (a) Release of organic substances (sCOD), (b) Release of ammonia nitrogen. Error bars represent the standard deviation (SD). 

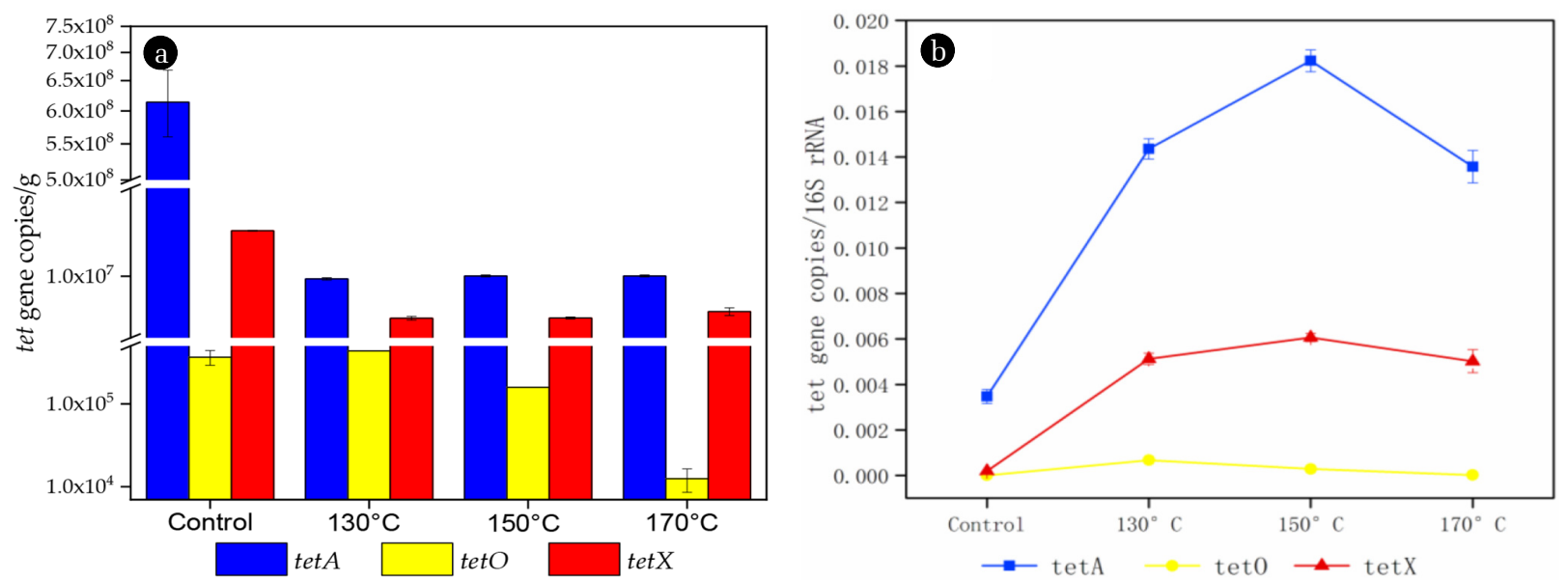

Fig. 2. Change of tet genes in OTC fermentation residue after hydrothermal treatment at different temperature levels (a) Absolute abundance (b) Relative abundance. The values are mean $+\mathrm{SD}$ of duplicates.

should be noted here that the three tet genes showed different reduction during the hydrothermal treatment (Fig. 2 (a)). The reason, on the one hand, may be that they have different temperature sensitivity due to the difference in their gene sequence structures such as the GC content [40]. On the other hand, this variation might also be attributed to the different tolerance of their resistant bacteria hosts to high temperature. Further study is required to uncover the mechanism behind the different response of ARGs to the hydrothermal pretreatment.

\subsection{Methane Formation Potential of the Hydrolyzed Residue}

Fig. 3 shows the cumulative methane yields of different digesters containing raw residue (control) and treated residues over a period of $23 \mathrm{~d}$. The cumulative methane yields were 73.7, 215.9, 656.8, and $439.0 \mathrm{NmL} \mathrm{CH}_{4} / \mathrm{gVS}$ for the control, $130^{\circ} \mathrm{C}, 150^{\circ} \mathrm{C}$, and $170^{\circ} \mathrm{C}$ treatments, respectively. Though the methane production profiles of the residues at $150^{\circ} \mathrm{C}$ and $170^{\circ} \mathrm{C}$ treatments did not reach the plateau, the above result already indicated that hydrothermal treatment at $150^{\circ} \mathrm{C}$ is the best choice among the tested three conditions for transforming the OTC fermentation residue into beneficial material for producing methane. The production of methane in the control was almost inhibited over the incubation period, which might be due to the high concentration of OTC in the raw residue inhibiting methanogenic metabolism. The inhibitory effect of anaerobic digestion process by OTC was reported previously by Beneragama et al. [41], who found that adding OTC at the dose of $30-90 \mathrm{mg} / \mathrm{L}$ in dairy manure resulted in 20.9\% - 31.4\% drop in methane yield. Recently, Tian et al. [26] found that OTC concentration higher than $4,180 \mathrm{mg} / \mathrm{kg}$ could severely inhibit methane production of mesophilic digestion using long-term chronic exposure experiment, due to the inhibition of fermenting and acidogenic bacteria. Besides removing the inhibitory effect of OTC, the hydrothermal pretreatment could also increase methane production as itself by hydrolyzing the OTC fermentation residue (Fig. 1 (a)). Interestingly, the methane yield of the OTC residue pretreated at $150^{\circ} \mathrm{C}$ was much higher than that at $130^{\circ} \mathrm{C}$, though the soluble COD concentration was similar for both conditions (Fig. 1 (a)). The residue pretreated at $150^{\circ} \mathrm{C}$ showed a shorter lag phase compared

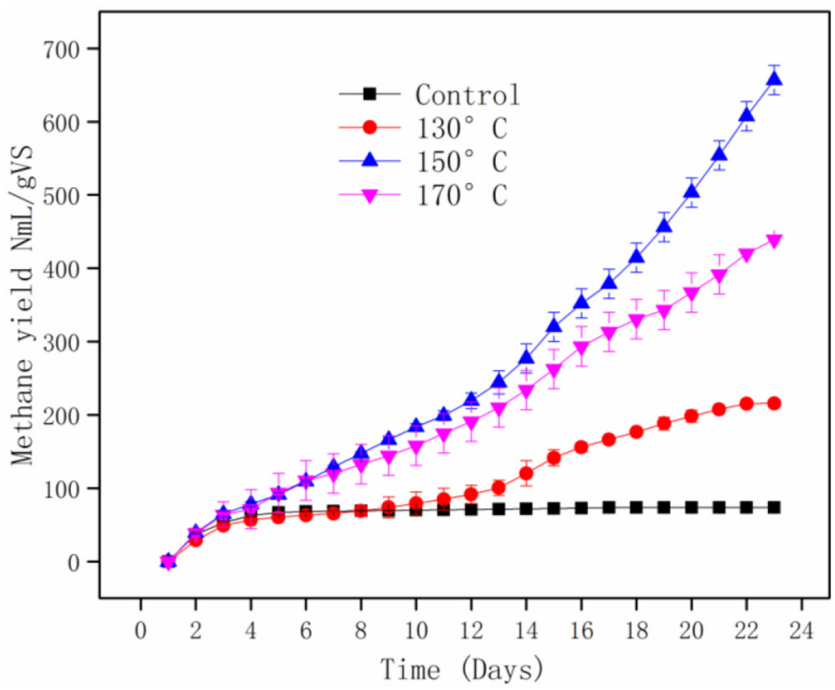

Fig. 3. Methane production of the raw and hydrolyzed OTC fermentation residues.

to other digesters and exhibited rapid methane formation. It is possible that the released biological macromolecules (e.g. proteins, complex sugars) were further transformed into smaller molecules such as monosaccharides and amino acids through further hydrolysis and degradation reactions [42, 43], which made them easier to be utilized for acetogenic and methanogenic metabolisms. Further increase of the temperature to $170^{\circ} \mathrm{C}$, however, also led to a lower methane production yield. Carrère et al. [44] investigated the impact of hydrothermal pretreatment over a temperature range of 60 $210^{\circ} \mathrm{C}$ on anaerobic digestion of waste activated sludge and found that methane production was enhanced up $190^{\circ} \mathrm{C}$ and further temperature increase adversely affected the process due to the formation of recalcitrant compounds, such as melanoidins and heterocyclic amines [45] depending on the condition of Maillard reaction and composition of reactants[46]. Dwyer et al. [47] also found more refractory COD was produced with the increase of temperature from 140 to $165^{\circ} \mathrm{C}$ during hydrothermal hydrolysis of activated 
sludge. Another possible reason may be the adverse impact of the relatively higher ammonia concentration $(976.6 \mathrm{mg} / \mathrm{L})$ at the $170^{\circ} \mathrm{C}$ treatment, since the concentration of ammonia nitrogen higher than $800 \mathrm{mg} / \mathrm{L}$ could disturb the stability of anaerobic digestion $[48,49]$.

\subsection{Changes of tet Genes after The BMP Test}

The abundances of tet genes were detected before and after the BMP test to evaluate the impact of the hydrolyzed OTC residue on resistance development (Fig. 4). The total copy number of each tet gene in the mixtures of the substrate and inoculum before the BMP test was considered as a reference value for the evaluation. After digestion, tet $A$ and tet $X$ were significantly $(p<0.01)$ reduced under all treatments including the control system. tet $O$ was enriched a little $(p<0.05)$ in the control, remained unchanged at $130^{\circ} \mathrm{C}$, and decreased to below the detection level $\left(2.9 \times 10^{2}\right.$ copies $\left./ \mu \mathrm{L}\right)$ at both 150 and $170^{\circ} \mathrm{C}$ treatments (Fig. 4). This result is in accordance with previous studies showing that mesophilic anaerobic digestion of sewage sludge could result in ARGs reduction even under antibiotic stresses [27, 37, 41, 50-52]. For example, Wang et al. [37] found that the ARGs removal efficiency of mesophilic digestion was approximately 50.8\%. Zhang et al. [52] reported that tetA and tet $X$ were significantly reduced when food waste was used as a substrate in mesophilic anaerobic digestion. It should be noted that short-term batch BMP test was used in this study with the main purpose to evaluate the methanogenic potential of treated residue, while long-term chronic exposure experiments should be performed to better check the induction of ARGs by the raw and thermo-hydrolyzed OTC residues.

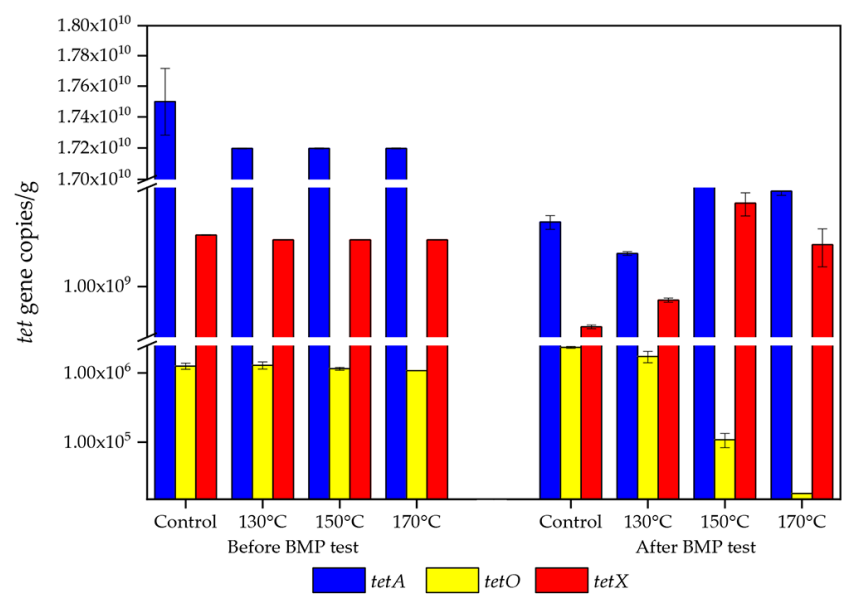

Fig. 4. Absolute abundances of tet genes in the mixtures of OTC fermentation residues and inoculum before and after the BMP test.

\subsection{Structure of Microbial Community after BMP Test}

The microbial communities of sludge samples before and after the BMP test were analyzed using Miseq Sequencing. As shown in Fig. 5, the control sludge bacterial community was clustered together with the inoculum, while the three systems with hydrothermal pretreatment were clustered together. The control system did not have much anaerobic digestion activities due to the inhibition effect of OTC, which might be the reason why it showed high similarity with the inoculum.

The sequences of bacterial communities were assigned to 15 phyla, with Firmicutes, Synergistetes, Bacteroidetes, and Thermotogae as the most predominant phyla in the four digesters (with relative abundance $>5.5 \%$ in all samples). As one of the most dominant phyla, Firmicutes occupied high proportions of $37.2 \%, 29.2 \%, 26.7 \%$, and $7.2 \%$ in digesters of the control, $130^{\circ} \mathrm{C}, 150^{\circ} \mathrm{C}$, and $170^{\circ} \mathrm{C}$ treatments, respectively. Members of Firmicutes phyla are important microorganisms involved in hydrolysis and fermentation during methanogenesis in anaerobic digestion [53, 54]. The other rare phyla include Proteobacteria, Fibrobacteres, Spirochaetae and Atribacteria. For the genus level, the most dominant genera were norank $f$ Synergistaceae, Mesotoga, Tepidimicrobium, and Proteiniphilum (relative abundance $>5.0 \%$ in most of the samples) (Fig. 5). Members of norank_f_Synergistaceae within the phylum Synergistetes are syntroph essential for methane production [55], which were abundant in all the treatments. Genera including Tepidimicrobium, Mobilitalea, Clostridium, Proteinphilum, Caldicoprobacter, Bacteroides, Macellibacteroides, Ruminococcus, and Acetanaerobacterium, all of which are common hydrolytic fermentative bacteria [56, 57], were enriched in the digesters fed with the hydrolyzed residues when compared with the control (Fig. 5). Their enrichment indicated an active methane metabolism in these digesters, which was consistent with the corresponding high methane productions revealed by the BMP test (Fig. 3). Proteiniphilum was especially enriched in the digested sludge of $150^{\circ} \mathrm{C}$ treatment with the relative abundance reaching $6.4 \%$ compared to $0.8 \%, 2.6 \%, 4.9 \%$ and $2.5 \%$ in the inoculum and samples of the control, $130^{\circ} \mathrm{C}$ and $170^{\circ} \mathrm{C}$ treatments, respectively (Fig. 5). Proteiniphilum belonging to family Porphyromonadaceae of phylum Bacteroidetes is known as amino acids degrader [58] and propionate-producing bacteria [59]. Zhang et al. [60] found that the presence of Proteiniphilum in anaerobic digestion was important for the optimization of volatile fatty acids composition and acceleration of methane production.

Based on our recent study [26], OTC mainly inhibits the fermenting and acidogenic bacteria of the methanogenic communities during mesophilic digestion, while methanogens remain active even under the OTC dose of $1,000 \mathrm{mg} / \mathrm{L}$. So, in this study, the primers set of 515F/907R, which mainly targets the bacterial 16S rRNA gene $[26,28]$, was used to follow the different response of microbial communities. However, considering the importance of methanogenic archaea for process stability and the primers set could also amplify archaeal 16S rRNA gene sequences. As shown in Table S3, the sequences belonging to archaea accounted for a very low ratio $(<5.5 \%)$ in the total sequence data in all the samples, which was in line with expectation considering the specificity of the primers. The result also indicated that the archaeal abundance is quite lower than the bacterial abundance, which was also consistent with previous studies [26]. As for the composition of the archaeal communities, Methanobacterium and Methanolinea were the dominant hydrogenotrophic methanogens, and Methanosaeta was the dominant aceticlastic methanogen in the inoculum and digested sludge samples after BMP test (Fig. S1 and Table S3). It suggested that further studies that use specific primers for detecting bacteria and archaea separately and are conducted for a longer anaerobic digestion time are required to have a better understanding of the microbial community features. 


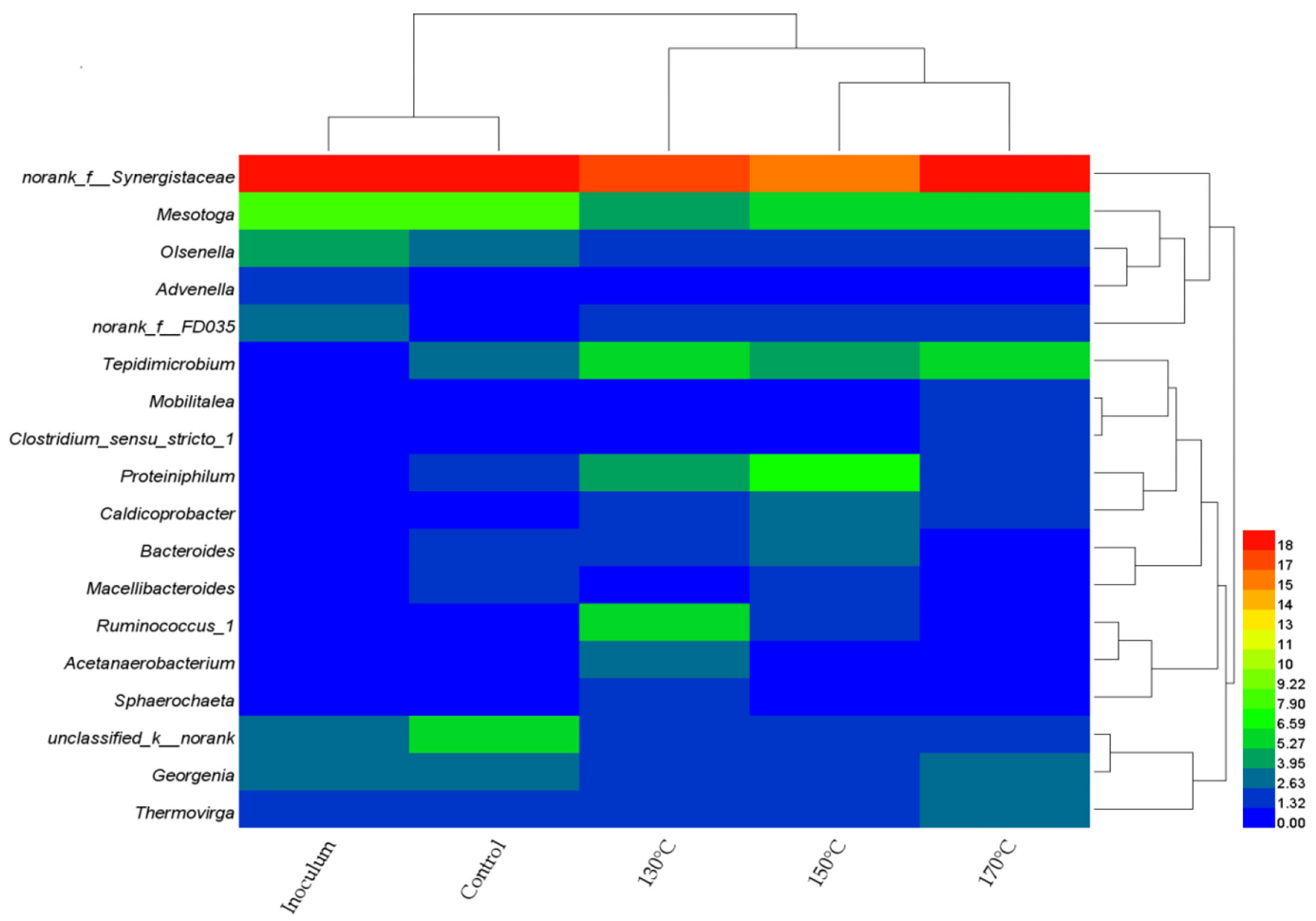

Fig. 5. Composition of bacterial communities at the genus level after the BMP test.

\section{Conclusions}

The present study investigated the effects of hydrothermal pretreatment on the removal of antibiotics from the OTC fermentation residue. Hydrothermal pretreatment at various temperatures of 130 $-170^{\circ} \mathrm{C}$ for $5 \mathrm{~min}$ efficiently removed the antibiotics (> 99.9\%), decreased the abundance of the tet genes, and increased the solubilization of organic matter in the substrate. Further use of the hydrolyzed substrate for methane production revealed that pretreatment at $150^{\circ} \mathrm{C}$ for $5 \mathrm{~min}$ resulted in significantly higher methane production and a further decrease in tet genes. Increasing pretreatment temperature to $170^{\circ} \mathrm{C}$ resulted in lower performance in methane production, probably caused by the formation of recalcitrant compounds and inhibition of ammonia. This study provides the basis for a feasible treatment option for OTC fermentation residue through the combination of anaerobic digestion with the hydrothermal pretreatment.

\section{Acknowledgment}

This research was funded by the National Natural Scientific Foundation of China, grant number 51978645; 21590814.

\section{Author Contributions}

M.A. (PhD) carried out the experiments, collected and analyzed the data and wrote the manuscript. Z.T. (PhD) conceived of the presented idea, carried out the experiments, and wrote the manuscript. Y.Z. (Professor) supervised the project, revised and approved the manuscript to be published. Y.M. (Professor) supervised the project, revised and approved the manuscript to be published. W.Y. (PhD) commented and contributed to the final manuscript. L.D. ( $\mathrm{PhD}$ ) commented and contributed to the final manuscript.

\section{References}

1. Petković H, Lukežič T, Šušković J. Biosynthesis of Oxytetracycline by Streptomyces rimosus: Past, Present and Future Directions in the Development of Tetracycline Antibiotics. Food Technol. Biotechnol. 2017;55:3-13.

2. Liu M, Zhang Y, Yang M, et al. Abundance and Distribution of Tetracycline Resistance Genes and Mobile Elements in an Oxytetracycline Production Wastewater Treatment System. Environ. Sci. Technol. 2012;46:7551-7557.

3. Publications UIB. China Ecology \& Nature Protection Handbook. Int'l Business Publications, 2009.

4. Li C, Zhang G, Zhang Z, et al. Hydrothermal pretreatment for biogas production from anaerobic digestion of antibiotic mycelial residue. Chem. Eng. J. 2015;279:530-537.

5. Shen Y, Zhuan R, Chu L, et al. Inactivation of antibiotic resistance genes in antibiotic fermentation residues by ionizing radiation: Exploring the development of recycling economy in antibiotic pharmaceutical factory. Waste Manag. 2019;84:141-146. 6. Trovó AG, Pupo Nogueira RF, Agüera A, et al. Degradation 
of the antibiotic amoxicillin by photo-Fenton process - Chemical and toxicological assessment. Water Res. 2011;45:1394-1402.

7. Li K, Yediler A, Yang M, et al. Ozonation of oxytetracycline and toxicological assessment of its oxidation by-products. Chemosphere 2008;72:473-478.

8. Qi Y, Wu S, Xi F, et al. Performance of a coupled micro-electrolysis, anaerobic and aerobic system for oxytetracycline (OTC) production wastewater treatment. J. Chem. Technol. Biotechnol. 2016;91:1290-1298.

9. Zhang X, Li R. Variation of antibiotics in sludge pretreatment and anaerobic digestion processes: Degradation and solid-liquid distribution. Bioresour. Technol. 2018;255:266-272.

10. Yi Q, Zhang Y, Gao Y, et al. Anaerobic treatment of antibiotic production wastewater pretreated with enhanced hydrolysis: Simultaneous reduction of COD and ARGs. Water Res. 2017;110:211-217.

11. Awad M, Tian Z, Gao Y, et al. Pretreatment of spiramycin fermentation residue using hyperthermophilic digestion: quick startup and performance. Water Sci. Technol. 2018;78:1823-1832.

12. Jo H (Brian), Parker W, Kianmehr P. Comparison of the impacts of thermal pretreatment on waste activated sludge using aerobic and anaerobic digestion. Water Sci Technol. 2018;78:1772-1781.

13. Yin J, Wang K, Yang Y, et al. Improving production of volatile fatty acids from food waste fermentation by hydrothermal pretreatment. Bioresour. Technol. 2014;171:323-329.

14. Rus E, Mills N, Shana A, et al. The intermediate thermal hydrolysis process: results from pilot testing and techno-economic assessment. Water Pract. Technol. 2017;12:406-422.

15. Bougrier $\mathrm{C}$, Delgenès JP, Carrère $\mathrm{H}$. Effects of thermal treatments on five different waste activated sludge samples solubilisation, physical properties and anaerobic digestion. Chem. Eng. J. 2008;139:236-244.

16. Pei J, Yao H, Wang H, et al. Comparison of ozone and thermal hydrolysis combined with anaerobic digestion for municipal and pharmaceutical waste sludge with tetracycline resistance genes. Water Res. 2016;99:122-128.

17. Zhang G, Ma D, Peng C, et al. Process characteristics of hydrothermal treatment of antibiotic residue for solid biofuel. Chem. Eng. J. 2014;252:230-238.

18. Zhong W, Li Z, Yang J, et al. Effect of thermal-alkaline pretreatment on the anaerobic digestion of streptomycin bacterial residues for methane production. Bioresour. Technol. 2014;151:436-440.

19. Ma D, Zhang G, Zhao P, et al. Hydrothermal treatment of antibiotic mycelial dreg: More understanding from fuel characteristics. Chem. Eng. J. 2015;273:147-155.

20. Tang M, Gu Y, Wei D, et al. Enhanced hydrolysis of fermentative antibiotics in production wastewater: Hydrolysis potential prediction and engineering application. Chem. Eng. J. 2019;123626.

21. Methods WEF-S. WEF - Standard Methods Available from: http://wef.org/resources/publications/books/StandardMethods/. Accessed April 14, 2020.

22. Qiao M, Chen W, Su J, et al. Fate of tetracyclines in swine manure of three selected swine farms in China. J. Environ. Sci. 2012;24:1047-1052.

23. Zhu Y-G, Johnson TA, Su J-Q, et al. Diverse and abundant antibiotic resistance genes in Chinese swine farms. Proc. Natl. Acad. Sci. 2013;110:3435-3440.
24. Griffin E, McMahon D, Mackie I, et al. Methanogenic population dynamics during start-up of anaerobic digesters treating municipal solid waste and biosolids. Biotechnol. Bioeng. 1998;57: 342-355.

25. Bolzonella D, Pavan P, Battistoni P, et al. Anaerobic digestion of waste activated sludge: influence of the solid retention time in the wastewater treatment process. Process Biochem. 2005;40:1453-1460.

26. Tian Z, Zhang Y, Yang M. Chronic impacts of oxytetracycline on mesophilic anaerobic digestion of excess sludge: Inhibition of hydrolytic acidification and enrichment of antibiotic resistome. Environ. Pollut. 2018;238:1017-1026.

27. Tian Z, Zhang Y, Yu B, et al. Changes of resistome, mobilome and potential hosts of antibiotic resistance genes during the transformation of anaerobic digestion from mesophilic to thermophilic. Water Res. 2016;98:261-269.

28. Xiong J, Liu Y, Lin X, et al. Geographic distance and $\mathrm{pH}$ drive bacterial distribution in alkaline lake sediments across Tibetan Plateau. Environ. Microbiol. 2012;14:2457-2466.

29. Deu-Pons J, Schroeder MP, Lopez-Bigas N. jHeatmap: an interactive heatmap viewer for the web. Bioinformatics 2014;30: 1757-1758.

30. Sun C, Li W, Chen Z, et al. Responses of antibiotics, antibiotic resistance genes, and mobile genetic elements in sewage sludge to thermal hydrolysis pre-treatment and various anaerobic digestion conditions. Environ. Int. 2019;133:105156.

31. Doi AM, Stoskopf MK. The Kinetics of Oxytetracycline Degradation in Deionized Water under Varying Temperature, $\mathrm{pH}$, Light, Substrate, and Organic Matter. J. Aquat. Anim. Health 2000;12:246-253.

32. Wang Q, Yates SR. Laboratory Study of Oxytetracycline Degradation Kinetics in Animal Manure and Soil. J. Agric. Food Chem. 2008;56:1683-1688.

33. Loke M-L, Jespersen S, Vreeken R, et al. Determination of oxytetracycline and its degradation products by high-performance liquid chromatography-tandem mass spectrometry in manure-containing anaerobic test systems. J. Chromatogr. B. 2003;783:11-23.

34. Zhang H, Zhang Y, Yang M, et al. Evaluation of residual antibacterial potency in antibiotic production wastewater using a real-time quantitative method. Environ. Sci. Process Impacts 2015;17:1923-1929.

35. Zhang G, Li C, Ma D, et al. Anaerobic digestion of antibiotic residue in combination with hydrothermal pretreatment for biogas. Bioresour. Technol. 2015;192:257-265.

36. González-Fernández C, Sialve B, Bernet N, et al. Thermal pretreatment to improve methane production of Scenedesmus biomass. Biomass Bioenergy 2012;40:105-111.

37. Wang M, Li R, Zhao Q. Distribution and removal of antibiotic resistance genes during anaerobic sludge digestion with alkaline, thermal hydrolysis and ultrasonic pretreatments. Front Environ. Sci. Eng. 2019;13:43.

38. Tong J, Lu X, Zhang J, et al. Occurrence of antibiotic resistance genes and mobile genetic elements in enterococci and genomic DNA during anaerobic digestion of pharmaceutical waste sludge with different pretreatments. Bioresour. Technol. 2017;235:316-324.

39. Karni M, Zidon D, Polak P, et al. Thermal Degradation of DNA. 
DNA Cell Biol. 2013;32:298-301.

40. Gunbin, Konstantin V, Afonnikov, Dmitry A, et al. Molecular evolution of the hyperthermophilic archaea of the Pyrococcus genus: analysis of adaptation to different environmental conditions. BMC Genomics. 2009; 10: 639.

41. Beneragama N, Moriya Y, Yamashiro T, et al. The survival of cefazolin-resistant bacteria in mesophilic co-digestion of dairy manure and waste milk. Waste Manag. Res. 2013;31:843-848.

42. Li C, Zhang G, Zhang Z, et al. Hydrothermal pretreatment for biogas production from anaerobic digestion of antibiotic mycelial residue. Chem. Eng. J. 2015;279:530-537.

43. Song S, Jiang M, Yao J, et al. Anaerobic digestion of spectinomycin mycelial residues pretreated by thermal hydrolysis: removal of spectinomycin and enhancement of biogas production. Environ. Sci. Pollut. Res. 2020.

44. Carrère H, Bougrier C, Castets D, et al. Impact of initial biodegradability on sludge anaerobic digestion enhancement by thermal pretreatment. J. Environ. Sci. Health Part A 2008;43:1551-1555.

45. Wang HY, Qian H, Yao WR. Melanoidins produced by the Maillard reaction: structure and biological activity. Food Chem. 2011; 128: 573-584.

46. Martins S, Jongen F, van S. A review of Maillard reaction in food and implications to kinetic modelling. Trends Food Sci. Technol. 2000;11:364-373.

47. Dwyer J, Starrenburg D, Tait S, et al. Decreasing activated sludge thermal hydrolysis temperature reduces product colour, without decreasing degradability. Water Res. 2008;42:4699-4709.

48. Moestedt J, Müller B, Westerholm M, et al. Ammonia threshold for inhibition of anaerobic digestion of thin stillage and the importance of organic loading rate. Microb. Biotechnol. 2016;9:180-194.

49. Yenigün O, Demirel B. Ammonia inhibition in anaerobic digestion: A review. Process Biochem. 2013;48:901-911.

50. Resende JA, Diniz CG, Silva VL, et al. Dynamics of antibiotic resistance genes and presence of putative pathogens during ambient temperature anaerobic digestion. J. Appl. Microbiol. 2014;117:1689-1699.

51. Diehl DL, LaPara TM. Effect of Temperature on the Fate of
Genes Encoding Tetracycline Resistance and the Integrase of Class 1 Integrons within Anaerobic and Aerobic Digesters Treating Municipal Wastewater Solids. Environ. Sci. Technol. 2010;44:9128-9133.

52. Zhang J, Mao F, Loh K-C, et al. Evaluating the effects of activated carbon on methane generation and the fate of antibiotic resistant genes and class I integrons during anaerobic digestion of solid organic wastes. Bioresour. Technol. 2018;249:729-736.

53. Liu C, Li H, Zhang Y, et al. Evolution of microbial community along with increasing solid concentration during high-solids anaerobic digestion of sewage sludge. Bioresour. Technol. 2016;216:87-94.

54. He Q, Li L, Zhao X, et al. Investigation of foaming causes in three mesophilic food waste digesters: reactor performance and microbial analysis. Sci. Rep. 2017;7:1-10.

55. Rincón, M.T.; Allison, M.J.; Michelangeli, F.; De Sanctis, T.; Domínguez-Bello, M.G. Anaerobic degradation of mimosine-derived hydroxypyridines by cell free extracts of the rumen bacterium Synergistes jonesii. FEMS Microbiol. Ecol. 1998, 27, 127-132.

56. Ma H, Wu M, Liu H, et al. Study on enhancing sludge methanogenesis by adding acetylene black and effect on the characteristics \& microbial community of anaerobic granular sludge. RSC Adv. 2019;9:23086-23095.

57. Jiang Y, Dennehy C, Lawlor PG, et al. Exploring the roles of and interactions among microbes in dry co-digestion of food waste and pig manure using high-throughput 16S rRNA gene amplicon sequencing. Biotechnol. Biofuels 2019;12:5.

58. Zeppilli M, Villano M, Aulenta F, et al. Effect of the anode feeding composition on the performance of a continuous-flow methane-producing microbial electrolysis cell. Environ. Sci. Pollut. Res. 2015;22:7349-7360.

59. Xiong Y, Harb M, Hong P-Y. Performance and microbial community variations of anaerobic digesters under increasing tetracycline concentrations. Appl. Microbiol. Biotechnol. 2017;101: 5505-5517.

60. Zhang J, Loh K-C, Lee J, et al. Three-stage anaerobic co-digestion of food waste and horse manure. Sci. Rep. 2017;7:1-10. 